\title{
Article \\ ZnO Thin Films Growth Optimization for Piezoelectric Application
}

\author{
Vincent Polewczyk ${ }^{1, *(D)}$, Riccardo Magrin Maffei ${ }^{2,3}{ }^{-}$, Giovanni Vinai ${ }^{1}$, Matteo Lo Cicero ${ }^{4}$, Stefano Prato ${ }^{4}$, \\ Pietro Capaldo ${ }^{1,5}{ }^{\circledR}$, Simone Dal Zilio $^{1}$, Alessandro di Bona ${ }^{2}$, Guido Paolicelli ${ }^{2}{ }^{\circledR}$, Andrea Mescola ${ }^{2}{ }^{\circledR}$, \\ Sergio D'Addato ${ }^{2,3}$, Piero Torelli ${ }^{1}$ and Stefania Benedetti ${ }^{2, *}$
}

check for

updates

Citation: Polewczyk, V.; Magrin Maffei, R.; Vinai, G.; Lo Cicero, M.; Prato, S.; Capaldo, P.; Dal Zilio, S.; di Bona, A.; Paolicelli, G.; Mescola, A.; et al. ZnO Thin Films Growth Optimization for Piezoelectric Application. Sensors 2021, 21, 6114. https://doi.org/10.3390/s21186114

Academic Editors:

Christopher Oshman,

Abhishek Singh Dahiya,

Guylaine Poulin-Vittrant and Charles Opoku

Received: 4 August 2021

Accepted: 8 September 2021

Published: 12 September 2021

Publisher's Note: MDPI stays neutral with regard to jurisdictional claims in published maps and institutional affiliations.

Copyright: (c) 2021 by the authors. Licensee MDPI, Basel, Switzerland. This article is an open access article distributed under the terms and conditions of the Creative Commons Attribution (CC BY) license (https:// creativecommons.org/licenses/by/ $4.0 /)$.
1 Laboratorio TASC, Istituto Officina dei Materiali (IOM)-CNR, 34149 Trieste, Italy; vinai@iom.cnr.it (G.V.); capaldo@iom.cnr.it (P.C.); dalzilio@iom.cnr.it (S.D.Z.); piero.torelli@elettra.eu (P.T.)

2 Istituto Nanoscienze-CNR, Via Campi 213/a, 41125 Modena, Italy; riccardo.magrinmaffei@unimore.it (R.M.M.); alessandro.dibona@nano.cnr.it (A.d.B.); guido.paolicelli@nano.cnr.it (G.P.); andrea.mescola@nano.cnr.it (A.M.); sergio.daddato@unimore.it (S.D.)

3 Dipartimento di Scienze Fisiche Informatiche Matematiche, Università di Modena e Reggio Emilia, Via Campi 213/a, 41125 Modena, Italy

4 A.P.E. Research srl, Area Science Park, Basovizza, ss14 Km 163.5, 34149 Trieste, Italy; matteo.locicero@aperesearch.com (M.L.C.); stefano.prato@aperesearch.com (S.P.)

5 Dipartimento di Fisica e Astronomia, Università di Padova, Via F Marzolo 8, 35131 Padova, Italy

* Correspondence: polewczyk@iom.cnr.it (V.P.); stefania.benedetti@nano.cnr.it (S.B.)

Abstract: The piezoelectric response of $\mathrm{ZnO}$ thin films in heterostructure-based devices is strictly related to their structure and morphology. We optimize the fabrication of piezoelectric $\mathrm{ZnO}$ to reduce its surface roughness, improving the crystalline quality, taking into consideration the role of the metal electrode underneath. The role of thermal treatments, as well as sputtering gas composition, is investigated by means of atomic force microscopy and x-ray diffraction. The results show an optimal reduction in surface roughness and at the same time a good crystalline quality when $75 \%$ $\mathrm{O}_{2}$ is introduced in the sputtering gas and deposition is performed between room temperature and $573 \mathrm{~K}$. Subsequent annealing at $773 \mathrm{~K}$ further improves the film quality. The introduction of Ti or Pt as bottom electrode maintains a good surface and crystalline quality. By means of piezoelectric force microscope, we prove a piezoelectric response of the film in accordance with the literature, in spite of the low $\mathrm{ZnO}$ thickness and the reduced grain size, with a unipolar orientation and homogenous displacement when deposited on Ti electrode.

Keywords: surface roughness; piezoelectricity; crystallinity; magnetron sputtering; metal electrodes; $\mathrm{ZnO}$; thin films

\section{Introduction}

Zinc oxide $(\mathrm{ZnO})$ is extensively studied and employed because of its many applications, e.g., in sensors, photovoltaics or in piezoelectric devices [1,2]. Ceramic materials exhibit a macroscopic piezoelectric response when its crystalline structure has an axis that lacks inversion symmetry, with dipole moments aligned along the same direction. In the case of $\mathrm{ZnO}$, this corresponds to the [0001] c-axis direction. $\mathrm{ZnO}$ has the advantage that it can be easily grown along its c-axis and in the form of a variety of nanostructures $[3,4]$. This fact has pushed the interest for this material in the field of sensors [5-7], actuators [8,9], and nanogenerators $[10,11]$, in spite of the fact that the $d_{33}$ coefficient is still about one order of magnitude lower than that of other common piezoelectric ceramic compounds [12]. In these applications, the typical $\mathrm{ZnO}$ film thickness is in the range of micrometers, with a maximum reported piezo response of tens of pm/V for an oriented or composite film [13-15], and up to $240 \mathrm{pm} / \mathrm{V}$ for V-doped $\mathrm{ZnO}[16,17]$. Reducing the thickness, the piezoelectric response decreases, due to the reduction in grain size and crystal quality, making more difficult the exploitation of $\mathrm{ZnO}$ advantages in nanofabrication and nanodevices, where 
thinner oxide films are required $[18,19]$. Several deposition methods have been exploited to obtain piezoelectric $\mathrm{ZnO}$ [3], such as the hydrothermal treatment [20], the sol-gel spin coating technique [21], the ultrasonic spray pyrolysis technique [22] or physical vapor deposition (PVD) methods, such as magnetron sputtering [23,24], pulsed laser deposition $[25,26]$ or laser molecular beam epitaxy [27]. Among them, PVD, and in particular magnetron sputter deposition, allow us to maintain a good control on the film growth conditions to obtain reproducible and controllable properties in c-axis-oriented $\mathrm{ZnO}$ films of tens to hundreds nm thickness [3]. As an example, sputter deposition allows obtaining good insulating films with controlled defects [28,29]. However, for sputter-deposited $\mathrm{ZnO}$ films, the typical $d_{33}$ values reported in the literature are of few $\mathrm{pm} / \mathrm{V}[30,31]$, lower than those obtained in films grown with other techniques. Values are particularly low when radio frequency (RF) is employed, due to generally smaller grains [32-35]. These small grains can reduce the effective displacement if their polarizations are not fully aligned, and the presence of impurities at grain boundaries can generate a large number of free electrons inside their structure, reducing the final resistivity. These free electrons move and screen the piezoelectric potential generated under mechanical actions, in turn reducing drastically its amplitude [36]. In spite of this, RF power has the advantage of producing stoichiometric films with a reduced roughness due to a well-controlled deposition rate [34]. This characteristic is important when the film has to be employed in heterostructures with an ultrathin top electrode, especially to improve the interface coupling properties $[19,37,38]$. To reach such a control over $\mathrm{ZnO}$ quality during sputter deposition, it is typically necessary to tune the growth parameters, such as gas pressure and mixture (e.g., with $\mathrm{O}_{2}$ ), target power density and deposition rate, as well as thermal treatments. Previous investigations have shown that the use of a high percentage of $\mathrm{O}_{2}$ in the gas mixture reduces the surface roughness in $\mathrm{ZnO}$ films $[39,40]$. An increased deposition temperature further improves the crystalline alignment along the c-axis, but it tends to increase surface roughness [41,42]. In addition, it is known that the resulting $\mathrm{ZnO}$ film quality, both roughness and c-axis orientation, strongly depends on the metal underneath $[30,43,44]$. In previous studies, several different metal films were used as bottom electrodes below the oxide film; however, with no clear optimization process $[30,39-42,45,46]$. The correct balance between these factors strongly determines the resulting piezoelectric response. While grain alignment along the [0001] c-axis and the control on polarity distribution ( $\mathrm{Zn}$ - or O-termination of the grains) are decisive to improve piezoelectric response [41,45,46], the low surface roughness determines from one side the final flatness of the exposed sample surface, and on the other side a reduction in piezo coefficient [47].

From this scenario, it is therefore important to investigate the oxide properties at reduced thickness, by following and controlling its structural and morphological evolution, together with the influence of the substrate or seed material, namely the bottom metal electrode.

In this work, we studied the combination of different growth parameters in sputter deposition, exploring the consequences on $\mathrm{ZnO}$ film quality in terms of roughness and crystal quality, also taking the effect of the substrate/bottom seed layer into consideration. We observed that the best condition is the use of $75 \% \mathrm{O}_{2}$ in the sputtering gas, together with a variable deposition temperature between room temperature (RT) and $573 \mathrm{~K}$. Further annealing at $773 \mathrm{~K}$ improves the film quality. When we apply this procedure on metal electrodes, the best results are obtained on Ti and Pt films, inducing a good piezoelectric response, more homogeneous in the vertical direction and unipolar in the case of the Ti electrode.

\section{Materials and Methods}

$\mathrm{ZnO}$ films were deposited by RF magnetron sputtering from a $\mathrm{ZnO} 3$ " target ( $\mathrm{ZnO}$ purity $99.99 \%$ ) about $15 \mathrm{~cm}$ from the substrate in $3 \times 10^{-6}$ mbar base pressure. To the oxide target was applied $120 \mathrm{~W}$ RF power, corresponding to a final rate between 0.04 and $0.1 \mathrm{~nm} . \mathrm{s}^{-1}$, depending on the gas mixture. Gas pressure of 5 mTorr was obtained with 
a mixture of $\mathrm{Ar}$ and $\mathrm{O}_{2}$, with oxygen content varying from 0 to $75 \%$, as described in the following section (flux 0-15 sccm). Film thickness was kept constant at $300 \mathrm{~nm}$ and was calibrated during the deposition by a quartz microbalance and checked after the growth by means of a profilometer. Deposition temperature was varied by resistive heating and measured with a calibrated thermocouple on the sample stage. Post-growth treatment was performed in air in a quartz tube furnace up to $973 \mathrm{~K}$ in a mixture of $50 \% \mathrm{~N}_{2}$ and $50 \%$ $\mathrm{O}_{2}$ flux. Substrates used for $\mathrm{ZnO}$ investigation (AFM, XRD) were n-doped Si(100) wafers covered by $680 \mathrm{~nm}$ thermal amorphous $\mathrm{SiO}_{2}$. The substrates were cleaned with acetone and isopropanol in an ultrasonic bath and dried with nitrogen.

Then, the established procedure was used to grow $\mathrm{ZnO}$ on several metal electrodes ( $\mathrm{Ti}, \mathrm{Pt}, \mathrm{Al}, \mathrm{Al} / \mathrm{Cr}$ and $\mathrm{Pt} / \mathrm{Cr}$ ). The thin metal films used as bottom electrodes were grown on $\mathrm{MgO}$ (001) substrates, after acetone and ethanol cleaning, at room temperature by means of electron beam evaporators in an atmosphere of around $5 \times 10^{-6} \mathrm{mbar}$ and a deposition rate of $0.01 \mathrm{~nm} . \mathrm{s}^{-1}$, with a total thickness of $25 \mathrm{~nm}$. Among the different metals used, here, we focus our study on the most promising ones, i.e., Pt and Ti. Similar measurements were, however, conducted on the other metals, and the results are shown in the Supplementary Material. The electrical resistance of the metal films was tested with a two-point probe after all preparation steps to check that sufficient electrical conductivity was left after the $\mathrm{ZnO}$ growth and the post-deposition treatments.

The morphology was investigated by means of an ambient pressure NTEGRA AURA NT-MDT Atomic Force Microscope (AFM) in semi-contact (tapping) mode with Si cantilevers. The crystallographic structure was characterized by X-Ray Diffraction (XRD), acquiring specular scans in $\theta-2 \theta$ geometry with a PanAnalytical X'Pert Pro diffractometer (Cu-K $\alpha$ wavelength). Piezo force microscopy (PFM) measurements were performed with an A.P.E. Research instrument (model A100-AFM Plus version) in contact mode. We used AppNano doped diamond DD-ACTA tips, with an applied force of $10 \mathrm{nN}$, a $4 \mathrm{~V}$ DC bias and a $\pm 3 \mathrm{~V}$ AC bias with a $10 \mathrm{kHz}$ frequency.

\section{Results}

The film piezoelectric response strictly depends on its surface morphology and crystalline order. We thus investigated the most important parameters of film deposition on a $\mathrm{SiO}_{2} / \mathrm{Si}$ support for a $300 \mathrm{~nm}$-thick $\mathrm{ZnO}$ film in order to obtain the best compromise.

\subsection{Temperature Optimization}

Figure 1a shows the AFM image of the surface of $\mathrm{ZnO}$ film deposited at room temperature. To investigate the effect of temperature alone, we introduced only Ar in the plasma during sputter deposition. The surface was composed of grains with an average lateral diameter of $70 \mathrm{~nm}$ and an RMS roughness of $6.3 \mathrm{~nm}$ (Figure 1c). In XRD plots, only the $\mathrm{ZnO}(0002)$ peak is visible, together with the substrate diffraction signal (Figure 1d). This confirms the well-oriented growth of $\mathrm{ZnO}$ along the c-axis, as reported in the literature $[3,24,48]$. The position of the (0002) peak is shifted to a smaller angle $\left(34.21^{\circ}\right)$ than the expected bulk value of $34.55^{\circ}$ [49]. This indicates an elongation along the c-axis of the wurtzite structure of the oxide (and typically an in-plane contraction due to elastic strain). The presence of amorphous silica on the substrate surface excludes an epitaxial origin of the compression. The same compression was assigned in previous works to the presence of defects in the oxide $[50,51]$. We previously demonstrated that our $\mathrm{ZnO}$ films grown at $\mathrm{RT}$ in Ar are over-stoichiometric in oxygen, due to the presence of $\mathrm{Zn}$ vacancies and $\mathrm{O}$ interstitials [29]. 

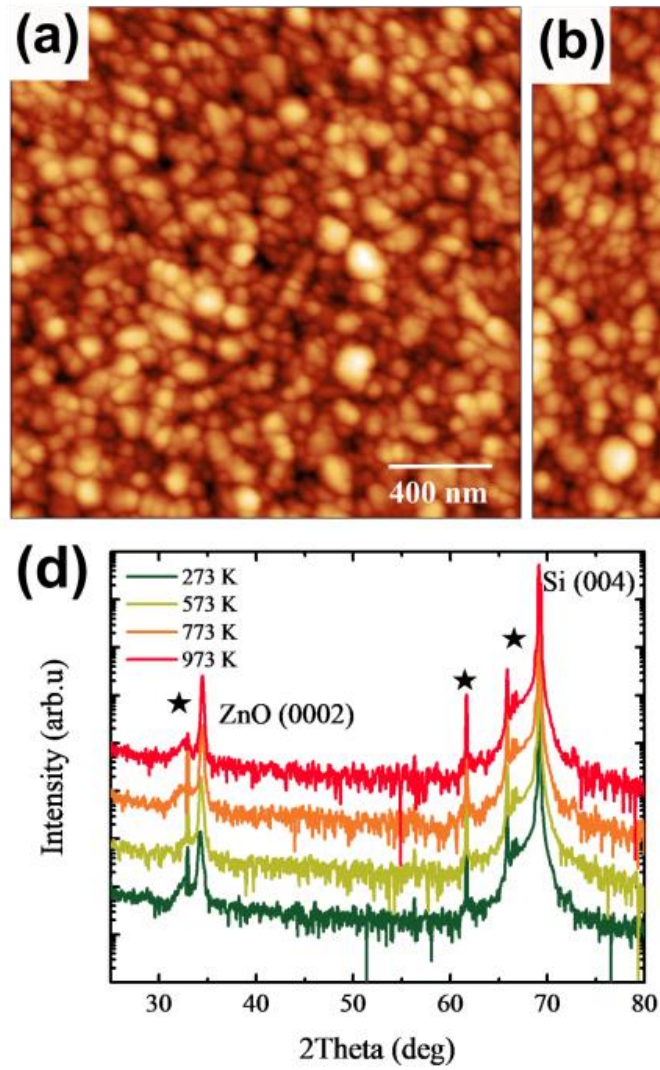

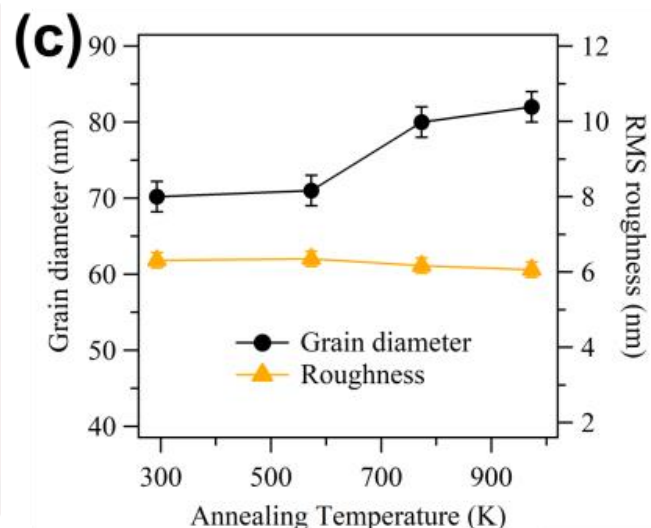

(e)

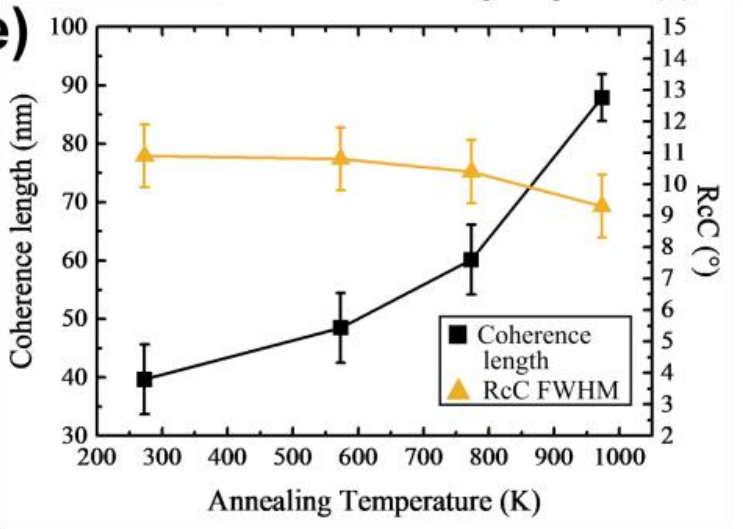

Figure 1. AFM images of size $2 \times 2 \mu \mathrm{m}^{2}$ (tapping mode) of (a) RT-grown $\mathrm{ZnO}$ film and (b) after post-growth annealing in $50 \% \mathrm{O}_{2}$ and $50 \% \mathrm{~N}_{2}$ at $773 \mathrm{~K}$. (c) Average grain diameter (black dot) and RMS roughness (orange triangle) as obtained by grain analysis of AFM images of surface shown in (a) as a function of annealing temperature. (d) XRD plots, (e) coherence length (black squares) and rocking curve FWHM (orange triangle) for increasing annealing temperature. The XRD signals are vertically shifted by a constant to better observe the differences. Stars in (d) indicate the replica peaks due to the non-monochromatized X-ray source.

Further indications of the crystalline quality of the film are the $2 \theta(0002)$ and the rocking curve $(\mathrm{RcC})$ full width at half maximum (FWHM) across the Bragg diffraction peak. The first is correlated with the coherence length by the Scherrer formula [52], representative of the size of the ordered crystalline domains along the axis perpendicular to the surface, while the RcC FWHM points out the grain alignment. Both values are reported in Figure 1e as a function of annealing temperature and are consistent with those reported in the literature [50,53].

When the film is annealed in a mixture of $50 \% \mathrm{O}_{2}$ and $50 \% \mathrm{~N}_{2}$ after the deposition, the surface changes, as shown in Figure 1b. The grain size progressively increases and the roughness slightly reduces (Figure 1c). However, the improvement is modest. Additionally, when increasing the annealing temperature, the position of the (0002) peak shifts towards the bulk value (reaching $34.47^{\circ}$ at $973 \mathrm{~K}$ ) and becomes narrower, while the FWHM of the rocking curve also improves (Figure 1e). The structural improvement is a hint of the removal of defects (most probably $\mathrm{O}$ interstitials) and of an increased coherence length and grain alignment (thus, smaller RcCs), consistent with the grain size enlargement. Therefore, the annealing temperature is effective in reducing defectivity and improving long range order. The domain size extracted from XRD measurements starts at RT from much lower values than those measured with AFM (Figure 1e). We attribute this difference to the smaller size of the crystalline domains inside the grains. However, when the film is post-annealed up to $973 \mathrm{~K}$, the crystalline domains and the grains almost coincide (Figures $1 \mathrm{e}$ and $1 \mathrm{c}$, respectively), indicating a strong ordering inside the grains and the removal of internal grain boundaries, as confirmed by the reduction in RcC FWHM. Small 
discrepancies can be related to the non-spherical shape of the grains, which have been often observed to be elongated along the c-axis $[3,39,54,55]$.

We therefore identify $773 \mathrm{~K}$ as the best compromise for post-growth annealing temperature to obtain surface quality improvements and being at the same time compatible with deposition on most metal electrodes that can be used in piezoelectric devices.

When the deposition temperature is increased to $573 \mathrm{~K}$, AFM image shows grains that increase in diameter to about $85 \mathrm{~nm}$ (Figure 2a), then reduce at $723 \mathrm{~K}$ (Figure 2b), followed by a continuous increase in roughness (Figure 2c). Compared to the results on surfaces after post-growth annealing (Figure 1c), here, we observe the formation of faceted grains that have a less smooth shape. At the same time, the (0002) peak is more intense, revealing the second-order $\mathrm{ZnO}$ (0004) diffraction peak (Figure 2d), and is closer to the bulk relaxed position $\left(34.41^{\circ}\right.$ at $723 \mathrm{~K}$ ), while the rocking curve dramatically shrinks (Figure 2e). This behavior is compatible with a reduced defect density and a better crystalline quality, improving with increasing temperature, related to the modifications of the grain size and shape, even if in this case the crystalline domains remain smaller than the grain size.
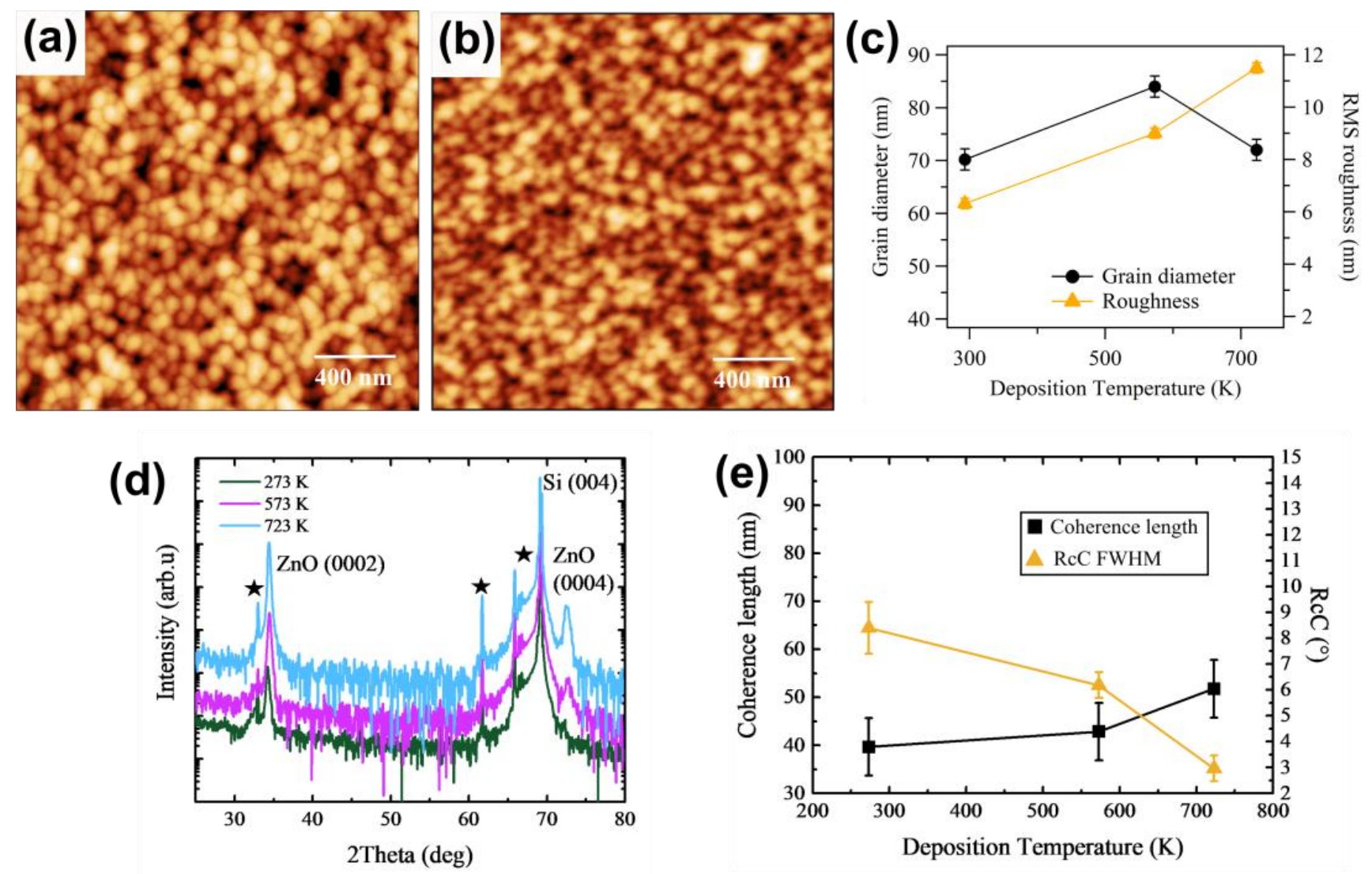

Figure 2. AFM images of size $2 \times 2 \mu \mathrm{m}^{2}$ of $300 \mathrm{~nm} \mathrm{ZnO}$ deposited at (a) $573 \mathrm{~K}$ and (b) $723 \mathrm{~K}$ in $100 \%$ Ar. (c) Average grain diameter (black dot) and RMS roughness (orange triangle) as obtained by grain analysis of AFM images of surfaces as a function of deposition temperature. (d) XRD plots, (e) coherence length (black squares) and rocking curve FWHM (orange triangles) for increasing deposition temperature. The XRD signals are vertically shifted to better observe the peaks.

Despite clear improvements in the crystalline quality with annealing treatmentseither post- or during growth - the surface roughness does not follow the same trend. This is consistent with previous works [41,42]; however, the RMS roughness has to be further reduced to be compatible with a heterostructure-based device implementation including an ultrathin top metal electrode. 


\subsection{Role of Oxygen in Sputtering Gas}

To accomplish this goal, we studied the use of oxygen introduced in the sputtering gas [39], combined with the best temperature conditions found before. The presence of oxygen in the sputtering plasma is expected to reduce the deposition rate and favor the growth with a lower final roughness. However, it can increase the already abundant presence of oxygen in the film, therefore increasing the density of $\mathrm{O}$ interstitials. Furthermore, it will also increase the electrical resistivity of the $\mathrm{ZnO}$ film [56,57], even if the films presented here are already insulating also in the absence of oxygen, probably due to the O defects that compensate for the presence of native $\mathrm{H}$ donors [28].

When $50 \% \mathrm{O}_{2}$ is added to the sputtering gas, the surface maintains a granular morphology, as shown in Figure 3a, but the surface roughness decreases markedly from 6.3 to $4.3 \mathrm{~nm}$, while the grain diameter decreases from 70 down to $42 \mathrm{~nm}$ (Figure 3c). Both roughness and grain size remain low when further increasing the oxygen content to $75 \%$ (Figure $3 \mathrm{~b})$. The (0002) $2 \theta$ peak shifts from $34.21^{\circ}$ to lower Bragg angle $\left(34.19^{\circ}\right.$, Figure $\left.3 \mathrm{~d}\right)$, with a slightly broader rocking curve FWHM (Figure 3e). As expected, the inclusion of more $\mathrm{O}$ interstitials leads to a higher deformation in the film. Finally, the coherence length increases and becomes higher than the grain size obtained from AFM measurements (Figure 3e). This can be assigned to the formation of grains elongated in the c-axis direction $[3,39,54,55]$, with a reduced degree of in-plane ordering. Since the piezoelectric response of the film is expected in the direction normal to the surface, i.e., [0001], we choose $75 \% \mathrm{O}_{2}$ as the most suitable for the device application. If we then combine the growth in $75 \%$ oxygen and a higher deposition temperature ( $573 \mathrm{~K}$-Figure $3 \mathrm{c}$ ), roughness further decreases, giving a final value of $2.1 \mathrm{~nm}$, while at the same time the mean grain size remains almost unchanged. On the other hand, the coherence length rises up to $68 \mathrm{~nm}$, keeping a relatively unchanged RcC (Figure 3e).
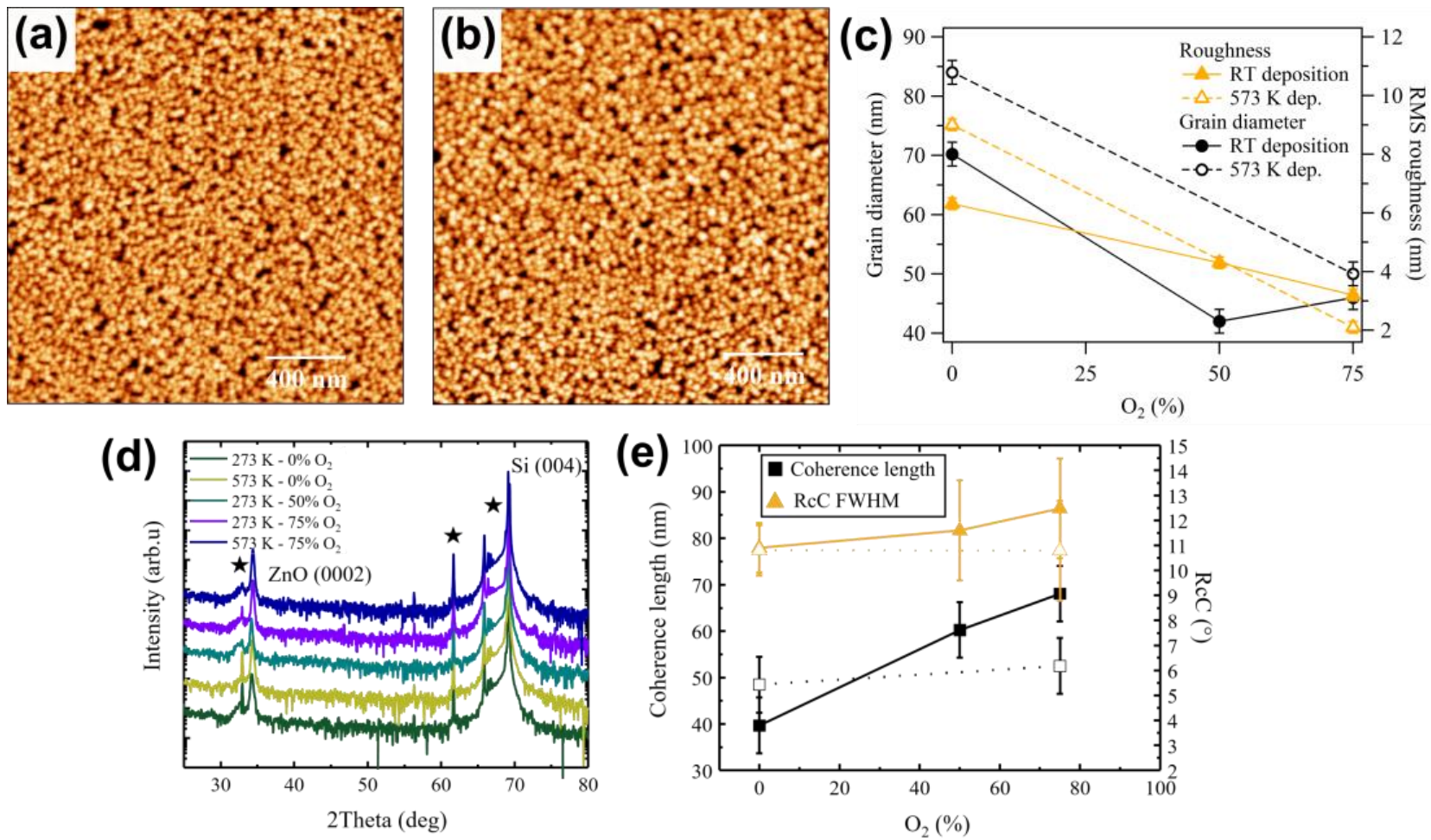

Figure 3. AFM images of size $2 \times 2 \mu \mathrm{m}^{2}$ of $\mathrm{ZnO}$ deposited with (a) $50 \%$ and (b) $75 \% \mathrm{O}_{2}$ at RT. (c) Average grain diameter (black dot) and RMS roughness (orange triangle) as obtained by grain analysis of AFM images of surface as a function of oxygen content during deposition. Empty markers are the corresponding curves obtained from films deposited at $573 \mathrm{~K}$. (d) XRD plots, (e) coherence length (black squares) and rocking curve FWHM (orange triangles) for increasing oxygen content for RT (fill triangles and squares) and $573 \mathrm{~K}$ depositions (empty triangles and squares). The XRD signals are vertically shifted by a constant. 
To further improve roughness and crystallinity, we performed the post-growth annealing at $773 \mathrm{~K}$ identified in Section 3.1. In this case, the improvement in terms of surface roughness is modest for the film grown at RT (from 3.1 to $2.6 \mathrm{~nm}$ ) and negligible for the $573 \mathrm{~K}$ film (not shown). Additionally, the XRD shows a significant decrease in the RcC FWHM, keeping a modest coherence length.

We can here conclude that the best procedure to grow optimized $300 \mathrm{~nm} \mathrm{ZnO} \mathrm{films} \mathrm{on}$ $\mathrm{SiO}_{2} / \mathrm{Si}$ happens through deposition by reactive sputtering with $75 \% \mathrm{O}_{2}$ (either at $\mathrm{RT}$ or $573 \mathrm{~K})$, followed by an annealing at $773 \mathrm{~K}$.

\subsection{Deposition on Metal Electrodes}

Finally, the choice of the substrate is fundamental for determining the properties of the sputtered film. If we then apply the best identified procedures for a $\mathrm{SiO}_{2} / \mathrm{Si}$ substrate on metal electrodes, the results are not trivial.

We chose several metal electrode films to be tested: $\mathrm{Ti}, \mathrm{Pt}, \mathrm{Al}, \mathrm{Al} / \mathrm{Cr}$ and $\mathrm{Pt} / \mathrm{Cr}$, all grown on $\mathrm{MgO}(001)$, with the metal thicknesses set to $25 \mathrm{~nm}$. The reduced metal thickness is motivated by the necessity to fabricate compact, low-cost devices and possibly patterned bottom electrodes such as those in [19]. Then, we checked by AFM and XRD the final quality of the obtained $\mathrm{ZnO}$ films. Despite similar deposition conditions, the results are extremely different. Grain size and roughness are significantly different as a function of the chosen metal, both being quite high for all metals except Ti and Pt. Consistently, the crystalline order is poor for all metal electrodes excluding Pt and Ti, with the (0002) Bragg peak sometimes hardly visible. The full data and AFM images are reported in the Supplementary Material. We show in Table 1 the values of surface quality and crystallinity for $\mathrm{Ti}$ and $\mathrm{Pt}$ electrodes. For $\mathrm{Ti}$ and $\mathrm{Pt}$, in contrast with the other metal supports, the surface roughness is low and the crystalline order is high, especially on Ti. Metallic Ti grows hexagonally on $\mathrm{MgO}(001)$ [58], while Pt tends to grow in (111) orientation at room temperature on $\mathrm{MgO}$ (001) [59]. Both metals thus favor $\mathrm{ZnO}(0001)$ growth with c-axis orientation, with Ti favoring a better order locally due to the smaller lattice mismatch $(10.1 \%)$ with respect to $\mathrm{Pt}(17.5 \%)$. Other metals have a more favorable matching with $\mathrm{MgO}(001)$ in a square epitaxy, and so a good ordering of zinc oxide is less favored.

Table 1. Measured experimental parameters of $\mathrm{ZnO}$ films on two different electrodes, $\mathrm{Pt}$ and Ti, deposited in $75 \% \mathrm{O}_{2}$ at $\mathrm{RT}$ and $573 \mathrm{~K}$, and then annealed at $773 \mathrm{~K}$ in $50 \% \mathrm{O}_{2}$ and $50 \% \mathrm{~N}_{2}$ atmosphere.

\begin{tabular}{|c|c|c|c|c|c|c|}
\hline $\begin{array}{l}\text { Bottom } \\
\text { Electrode }\end{array}$ & $\begin{array}{l}\text { Deposition } \\
\text { Conditions }\end{array}$ & $\begin{array}{l}\text { RMS Roughness } \\
\text { (nm) }\end{array}$ & $\begin{array}{c}\text { Grain } \\
\text { Diameter (nm) }\end{array}$ & Bragg Peak $\left({ }^{\circ}\right)$ & $\begin{array}{l}\text { Coherence } \\
\text { Length (nm) }\end{array}$ & $\begin{array}{c}\text { RcC of the }(0002) \\
\text { Bragg Peak }\left({ }^{\circ}\right)\end{array}$ \\
\hline \multirow[t]{4}{*}{$\mathrm{Pt}$} & $273 \mathrm{~K}$ & $3.4 \pm 0.5$ & $49 \pm 3$ & $34.21 \pm 0.02$ & $30 \pm 4$ & $>20$ \\
\hline & Annealed $773 \mathrm{~K}$ & $3.5 \pm 0.3$ & $54 \pm 3$ & $34.34 \pm 0.02$ & $42 \pm 3$ & $>20$ \\
\hline & $573 \mathrm{~K}$ & $6.0 \pm 0.2$ & $55 \pm 5$ & $34.31 \pm 0.02$ & $33 \pm 4$ & $>20$ \\
\hline & Annealed $773 \mathrm{~K}$ & $4.5 \pm 0.4$ & $70 \pm 5$ & $34.39 \pm 0.02$ & $104 \pm 2$ & $>20$ \\
\hline \multirow[t]{4}{*}{$\mathrm{Ti}$} & $273 \mathrm{~K}$ & $2.3 \pm 0.3$ & $39 \pm 4$ & $34.28 \pm 0.02$ & $39 \pm 3$ & $16 \pm 2$ \\
\hline & Annealed $773 \mathrm{~K}$ & $15.2 \pm 1$ & $130 \pm 8$ & $34.37 \pm 0.02$ & $102 \pm 2$ & $7 \pm 2$ \\
\hline & $573 \mathrm{~K}$ & $3.4 \pm 0.2$ & $43 \pm 3$ & $34.33 \pm 0.02$ & $80 \pm 2$ & $3 \pm 1$ \\
\hline & Annealed $773 \mathrm{~K}$ & $2.3 \pm 0.3$ & $44 \pm 2$ & $34.39 \pm 0.02$ & $115 \pm 2$ & $3 \pm 1$ \\
\hline
\end{tabular}

As already observed on Si substrates, in these cases the $\mathrm{ZnO}$ thin films are also strained at RT due to the presence of defects, but become relaxed when the deposition temperature is rising. The thermal treatment increases the quality of the films, reducing the FWHM of the RcC and increasing the coherence length, along with keeping a low surface roughness. After the post-growth annealing, a coherent length up to a hundred nm (better than in the case of $\mathrm{SiO}_{2} / \mathrm{Si}$ substrate) is found in most of the measured cases. The best structural and morphological properties are found on the Ti electrode. These points highlight the importance of the seed layer, and that a compromise should be found. 


\subsection{Piezoelectric Properties}

To conclude our investigation of the characterization of the film for device applications, we measured the piezoelectric response by means of PFM on the $\mathrm{ZnO}$ films grown at RT and $573 \mathrm{~K}$ on Pt and Ti bottom electrodes. A sketch of the PFM measurement configuration is shown in the Supplementary Material. The resulting PFM images are shown in Figure 4 for the different studied cases: $\mathrm{ZnO} / \mathrm{Ti}$ deposited at $\mathrm{RT}$ (a) and at $573 \mathrm{~K}$ (b), and $\mathrm{ZnO} / \mathrm{Pt}$ deposited at RT (c) and at $573 \mathrm{~K}(\mathrm{~d})$. The images show the effective piezoelectric response extracted from topography, PFM displacement and phase responses (see Figure S7) when an alternating voltage of $\pm 3 \mathrm{~V}$ over a continuous $4 \mathrm{~V}$ voltage is applied between the tip, acting as a top electrode, and the bottom metal electrode. We choose $4 \pm 3 \mathrm{~V}$ to remain below the breakdown voltage expected for $\mathrm{ZnO}$ thin films [60]. No initial applied bias was used to polarize the samples. For [0001]-oriented $\mathrm{ZnO}$, this response should be dominated by the vertical displacement over the in-plane piezo coefficients.
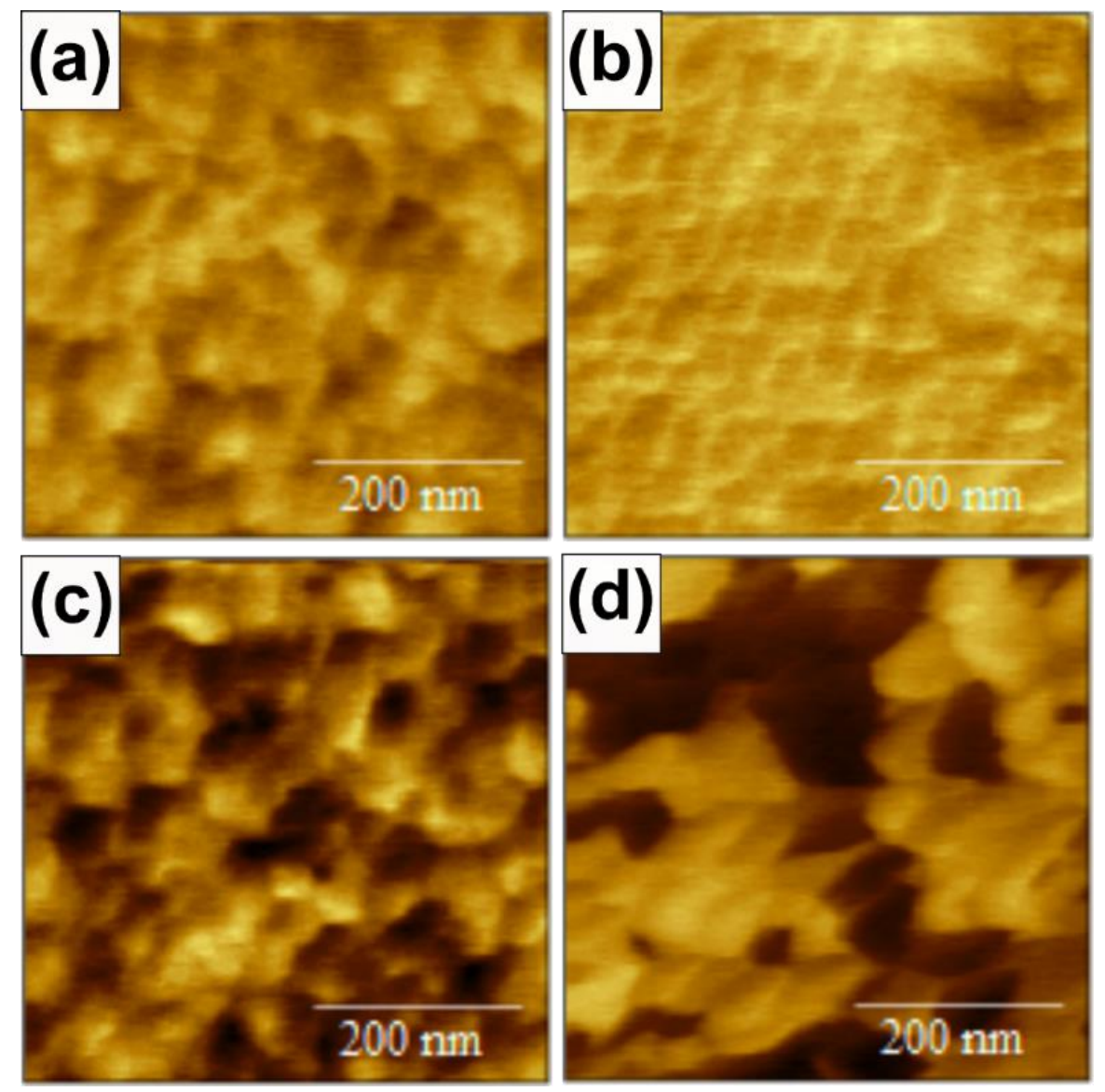

Figure 4. PFM images of size $0.5 \times 0.5 \mu \mathrm{m}^{2}$ of $\mathrm{ZnO}$ deposited with $75 \% \mathrm{O}_{2}$ at $\mathrm{RT}(\mathbf{a}, \mathbf{c})$ and at $573 \mathrm{~K}$ $(\mathbf{b}, \mathbf{d})$ on $\mathrm{Ti}(\mathbf{a}, \mathbf{b})$ and on $\mathrm{Pt}(\mathbf{c}, \mathbf{d})$. The contrast represents the effective piezoelectric response for an applied alternating voltage of $\pm 3 \mathrm{~V}$ over a continuous bias voltage of $4 \mathrm{~V}$.

Figure 4 highlights drastically different contrasts on the different $\mathrm{ZnO}$ surfaces. As observed in [61], different $\mathrm{ZnO}$ grains present different piezo properties, which could be detrimental for device applications. In the images, we can observe that $\mathrm{ZnO}$ on $\mathrm{Ti}$ deposited at $573 \mathrm{~K}$ has a quite homogeneous response (Figure $4 \mathrm{~b}$ ). On the contrary, on $\mathrm{Pt}$ deposited at $573 \mathrm{~K}$, opposite contrasts are observed when passing from one grain to another, corresponding to fully opposite phases (Figure $4 \mathrm{~d}$ ). The images indicate the presence of only two orientations, assigned to (0001) and (0001) polarity, as evidenced also in XRD. Similar observations with much reduced contrast can be made for the two other cases 
deposited at RT (Figure 4a,c). As a consequence, we can state that on Ti electrodes the $\mathrm{ZnO}$ film has a unique polarity, as highly desirable for piezo applications $[41,45,46]$.

To carefully evaluate the full piezo response, in-plane PFM was also tested, where no signal was observed (not shown here). Considering that we have essentially vertical displacement, we obtain $1.5 \pm 0.3$ and $1.9 \pm 0.3 \mathrm{pm} \cdot \mathrm{V}^{-1}$ for deposition on Ti at RT and $573 \mathrm{~K}, 1.4 \pm 0.3$ and approx. $1.5 \pm 0.3 \mathrm{pm} \cdot \mathrm{V}^{-1}$ for deposition on $\mathrm{Pt}$ at $\mathrm{RT}$ and $573 \mathrm{~K}$, respectively. Despite no initial bias used to fully polarize the samples, these values are comparable with those reported in the literature for $\mathrm{ZnO}$ films obtained by RF sputter deposition [30-35].

\section{Conclusions}

We studied the combination of sputtering gas composition and temperature treatments during the fabrication of $300 \mathrm{~nm}$-thick $\mathrm{ZnO}$ films to obtain the best film quality in terms of surface roughness and crystal quality. We observed that the best condition is the use of $75 \%$ $\mathrm{O}_{2}$ in the sputtering gas, together with a variable deposition temperature between RT and $573 \mathrm{~K}$. In these conditions, the film has a surface roughness around 2-3 nm when deposited on $\mathrm{SiO}_{2} / \mathrm{Si}$, a good orientation of the film along the c-axis and columnar grains of about $45 \mathrm{~nm}$ diameter in the surface plane. Some degree of disorder is due to the presence of defects, most probably $\mathrm{O}$ interstitials. When we apply this procedure for the growth of $\mathrm{ZnO}$ on different metal bottom electrodes, the best results are obtained in the case of $\mathrm{Pt}$ and Ti films, inducing a moderate piezoelectric response, with only vertical displacement and a homogeneous polarity orientation in the case of Ti. On other metals the growth is completely different, with high roughness and a poor crystalline quality.

Supplementary Materials: The following images/table are available online at https:/ /www.mdpi. com/article/10.3390/s21186114/s1, Figure S1: AFM of $300 \mathrm{~nm}$ ZnO grown on Ti and Pt on MgO(001) at RT and $573 \mathrm{~K}$; Figure S2: XRD $\theta-2 \theta$ scans on $\mathrm{ZnO}$ film on Pt and Ti on $\mathrm{MgO}(001)$; Figure S3: AFM images of $\mathrm{ZnO}$ grown on Pt and Ti after post-growth annealing at $773 \mathrm{~K}$; Figure S4: AFM images of $\mathrm{ZnO}$ grown other metal electrodes; Figure S5: XRD $\theta-2 \theta$ scans on $\mathrm{ZnO}$ on other metal electrodes on $\mathrm{MgO}(001)$; Figure S6: Sketch of PFM and film heterostructure; Figure S7: Topography, phase and amplitude measured in PFM on ZnO films grown on Pt and Ti at RT and 573 K; Table S1: Measured experimental parameters from AFM images of $\mathrm{ZnO}$ films on the different electrodes, deposited in $75 \% \mathrm{O}_{2}$ at $\mathrm{RT}$ and $573 \mathrm{~K}$.

Author Contributions: Conceptualization, P.T., S.B. and V.P.; Methodology, P.T., S.B. and V.P.; Formal Analysis, V.P. and R.M.M.; Investigation, V.P., R.M.M. and M.L.C.; Resources, A.d.B., G.P. and A.M.; Data Curation, V.P. and R.M.M.; Writing-Original Draft Preparation, S.B.; Writing-Review and Editing, V.P., R.M.M., G.V., P.T., A.d.B., G.P., A.M., S.D., M.L.C., S.P., P.C. and S.D.Z.; Supervision, P.T., S.B. and S.D.A.; Funding Acquisition, P.T. All authors have read and agreed to the published version of the manuscript.

Funding: This research was funded by NFFA-MUR Italy Progetti Internazionali.

Institutional Review Board Statement: Not applicable.

Informed Consent Statement: Not applicable.

Data Availability Statement: The data that support the findings of this study are available from the corresponding authors upon reasonable request.

Acknowledgments: This work has been partially performed in the framework of the Nanoscience Foundry and Fine Analysis (NFFA-MUR Italy Progetti Internazionali) project (www.trieste.NFFA.eu).

Conflicts of Interest: The authors declare no conflict of interest. 


\section{References}

1. Ozgur, U.; Hofstetter, D.; Morkoc, H. ZnO Devices and Applications: A Review of Current Status and Future Prospects. Proc. IEEE 2010, 98, 1255-1268. [CrossRef]

2. Borysiewicz, M.A. ZnO as a Functional Material, a Review. Crystals 2019, 9, 505. [CrossRef]

3. Ozgur, U.; Alivov, Y.I.; Liu, C.; Teke, A.; Reshchikov, M.A.; Dogan, S.; Avrutin, V.; Cho, S.J.; Morkoc, H. A comprehensive review of $\mathrm{ZnO}$ materials and devices. J. Appl. Phys. 2005, 98, 11. [CrossRef]

4. Wang, Z.L. Nanostructures of zinc oxide. Mater. Today 2004, 7, 26-33. [CrossRef]

5. Bhati, V.S.; Hojamberdiev, M.; Kumar, M. Enhanced sensing performance of ZnO nanostructures-based gas sensors: A review. Energy Rep. 2020, 6, 46-62. [CrossRef]

6. Chaudhary, S.; Umar, A.; Bhasin, K.K.; Baskoutas, S. Chemical Sensing Applications of ZnO Nanomaterials. Materials 2018, 11, 287. [CrossRef] [PubMed]

7. Elhosni, M.; Elmazria, O.; Petit-Watelot, S.; Bouvot, L.; Zhgoon, S.; Talbi, A.; Hehn, M.; Aissa, K.A.; Hage-Ali, S.; Lacour, D.; et al. Magnetic field SAW sensors based on magnetostrictive-piezoelectric layered structures: FEM modeling and experimental validation. Sens. Actuators A-Phys. 2016, 240, 41-49. [CrossRef]

8. Lee, J.B.; Kim, H.J.; Kim, S.G.; Hwang, C.S.; Hong, S.H.; Shin, Y.H.; Lee, N.H. Deposition of ZnO thin films by magnetron sputtering for a film bulk acoustic resonator. Thin Solid Films 2003, 435, 179-185. [CrossRef]

9. Yan, Z.; Zhou, X.Y.; Pang, G.K.H.; Zhang, T.; Liu, W.L.; Cheng, J.G.; Song, Z.T.; Feng, S.L.; Lai, L.H.; Chen, J.Z.; et al. ZnO-based film bulk acoustic resonator for high sensitivity biosensor applications. Appl. Phys. Lett. 2007, 90, 143503. [CrossRef]

10. Savarimuthu, K.; Sankararajan, R.; Govindaraj, R.; Narendhiran, S. A comparative study on a flexible ZnO-based nano-generator using Schottky and p-n junction contact for energy harvesting applications. Nanoscale 2018, 10, 16022-16029. [CrossRef] [PubMed]

11. Tlemcani, T.S.; Justeau, C.; Nadaud, K.; Alquier, D.; Poulin-Vittrant, G. Fabrication of Piezoelectric ZnO Nanowires Energy Harvester on Flexible Substrate Coated with Various Seed Layer Structures. Nanomaterials 2021, 11, 1433. [CrossRef]

12. Sun, F.; Khassaf, H.; Alpay, S.P. Strain engineering of piezoelectric properties of strontium titanate thin films. J. Mater. Sci. 2014, 49, 5978-5985. [CrossRef]

13. Christman, J.A.; Woolcott, R.R.; Kingon, A.I.; Nemanich, R.J. Piezoelectric measurements with atomic force microscopy. Appl. Phys. Lett. 1998, 73, 3851-3853. [CrossRef]

14. Abu Ali, T.; Pilz, J.; Schaffner, P.; Kratzer, M.; Teichert, C.; Stadlober, B.; Coclite, A.M. Piezoelectric Properties of Zinc Oxide Thin Films Grown by Plasma-Enhanced Atomic Layer Deposition. Phys. Status Solidi A-Appl. Mater. Sci. 2020, 217, 2000319. [CrossRef]

15. Garcia-Farrera, B.; Velasquez-Garcia, L.F. Ultrathin Ceramic Piezoelectric Films via Room-Temperature Electrospray Deposition of ZnO Nanoparticles for Printed GHz Devices. ACS Appl. Mater. Interfaces 2019, 11, 29167-29176. [CrossRef] [PubMed]

16. Yang, Y.C.; Song, C.; Wang, X.H.; Zeng, F.; Pan, F. Giant piezoelectric d(33) coefficient in ferroelectric vanadium doped ZnO films. Appl. Phys. Lett. 2008, 92, 012907. [CrossRef]

17. Fan, Q.Q.; Li, D.N.; Li, J.H.; Wang, C.H. Structure and piezoelectricity properties of V-doped ZnO thin films fabricated by sol-gel method. J. Alloys Compd. 2020, 829, 154483. [CrossRef]

18. Ion, V.; Craciun, F.; Scarisoreanu, N.D.; Moldovan, A.; Andrei, A.; Birjega, R.; Ghica, C.; Di Pietrantonio, F.; Cannata, D.; Benetti, M.; et al. Impact of thickness variation on structural, dielectric and piezoelectric properties of (Ba, Ca) (Ti, $\mathrm{Zr}) \mathrm{O}-3$ epitaxial thin films. Sci. Rep. 2018, 8, 2056. [CrossRef]

19. Polewczyk, V.; Vinai, G.; Motti, F.; Dal Zilio, S.; Capaldo, P.; Sygletou, M.; Benedetti, S.; Rossi, G.; Torelli, P. Original design of a patterned multiferroic heterostructure for electrical control of the magnetic shape anisotropy. J. Magn. Magn. Mater. 2020, 507, 166816. [CrossRef]

20. Zviagin, A.S.; Chernozem, R.V.; Surmeneva, M.A.; Pyeon, M.; Frank, M.; Ludwig, T.; Tutacz, P.; Ivanov, Y.F.; Mathur, S.; Surmenev, R.A. Enhanced piezoelectric response of hybrid biodegradable 3D poly(3-hydroxybutyrate) scaffolds coated with hydrothermally deposited ZnO for biomedical applications. Eur. Polym. J. 2019, 117, 272-279. [CrossRef]

21. Khan, M.I.; Bhatti, K.A.; Qindeel, R.; Alonizan, N.; Althobaiti, H.S. Characterizations of multilayer ZnO thin films deposited by sol-gel spin coating technique. Results Phys. 2017, 7, 651-655. [CrossRef]

22. Lee, Y.; Kim, H.; Roh, Y. Deposition of ZnO thin films by the ultrasonic spray pyrolysis technique. Jpn. J. Appl. Phys. Part 1-Regul. Pap. Short Notes Rev. Pap. 2001, 40, 2423-2428. [CrossRef]

23. Lu, J.G.; Ye, Z.Z.; Zeng, Y.J.; Zhu, L.P.; Wang, L.; Yuan, J.; Zhao, B.H.; Liang, Q.L. Structural, optical, and electrical properties of (Zn,Al)O films over a wide range of compositions. J. Appl. Phys. 2006, 100, 073714. [CrossRef]

24. Ellmer, K. Magnetron sputtering of transparent conductive zinc oxide: Relation between the sputtering parameters and the electronic properties. J. Phys. D-Appl. Phys. 2000, 33, R17-R32. [CrossRef]

25. Triboulet, R.; Perriere, J. Epitaxial growth of ZnO films. Prog. Cryst. Growth Charact. Mater. 2003, 47, 65-138. [CrossRef]

26. Ohtomo, A.; Tsukazaki, A. Pulsed laser deposition of thin films and superlattices based on ZnO. Semicond. Sci. Technol. 2005, 20, S1-S12. [CrossRef]

27. Opel, M.; Geprags, S.; Althammer, M.; Brenninger, T.; Gross, R. Laser molecular beam epitaxy of ZnO thin films and heterostructures. J. Phys. D-Appl. Phys. 2014, 47, 034002. [CrossRef]

28. Valenti, I.; Benedetti, S.; Di Bona, A.; Lollobrigida, V.; Perucchi, A.; Di Pietro, P.; Lupi, S.; Valeri, S.; Torelli, P. Electrical, optical, and electronic properties of Al:ZnO films in a wide doping range. J. Appl. Phys. 2015, 118, 165304. [CrossRef] 
29. Benedetti, S.; Valenti, I.; di Bona, A.; Vinai, G.; Castan-Guerrero, C.; Valeri, S.; Catellani, A.; Ruini, A.; Torelli, P.; Calzolari, A. Spectroscopic identification of the chemical interplay between defects and dopants in Al-doped ZnO. Phys. Chem. Chem. Phys. 2017, 19, 29364-29371. [CrossRef]

30. Ali, W.R.; Prasad, M. Piezoelectric MEMS based acoustic sensors: A review. Sens. Actuators A-Phys. 2020, 301, 111756. [CrossRef]

31. Trolier-McKinstry, S.; Muralt, P. Thin film piezoelectrics for MEMS. J. Electroceramics 2004, 12, 7-17. [CrossRef]

32. Kang, S.J.; Joung, Y.H. Influence of substrate temperature on the optical and piezoelectric properties of $\mathrm{ZnO}$ thin films deposited by rf magnetron sputtering. Appl. Surf. Sci. 2007, 253, 7330-7335. [CrossRef]

33. Sharma, P.; Guler, Z.; Jackson, N. Development and characterization of confocal sputtered piezoelectric zinc oxide thin film. Vacuum 2021, 184, 109930. [CrossRef]

34. Schuler, L.P.; Alkaisi, M.M.; Miller, P.; Reeves, R.J.; Markwitz, A. Comparison of DC and RF sputtered zinc oxide films with post-annealing and dry etching and effect on crystal composition. Jpn. J. Appl. Phys. Part 1-Regul. Pap. Brief Commun. Rev. Pap. 2005, 44, 7555-7560. [CrossRef]

35. Laurenti, M.; Stassi, S.; Lorenzoni, M.; Fontana, M.; Canavese, G.; Cauda, V.; Pirri, C.F. Evaluation of the piezoelectric properties and voltage generation of flexible zinc oxide thin films. Nanotechnology 2015, 26, 215704. [CrossRef] [PubMed]

36. Tao, R.; Mouis, M.; Ardila, G. Unveiling the Influence of Surface Fermi Level Pinning on the Piezoelectric Response of Semiconducting Nanowires. Adv. Electron. Mater. 2018, 4, 1700299. [CrossRef]

37. El Haimeur, A.; Slassi, A.; Pershin, A.; Cornil, D.; Makha, M.; Blanco, E.; Dominguez, M.; Bakkali, H. Reducing p-type Schottky contact barrier in metal/ZnO heterostructure through Ni-doping. Appl. Surf. Sci. 2021, 545, 149023. [CrossRef]

38. Saha, J.K.; Billah, M.M.; Jang, J. Triple-Stack ZnO/AlZnO/YZnO Heterojunction Oxide Thin-Film Transistors by Spray Pyrolysis for High Mobility and Excellent Stability. ACS Appl. Mater. Interfaces 2021, 13, 37340-37352. [CrossRef]

39. Park, S.H.; Seo, B.C.; Park, H.D.; Yoon, G. Film bulk acoustic resonator fabrication for radio frequency filter applications. Jpn. J. Appl. Phys. Part 1-Regul. Pap. Brief Commun. Rev. Pap. 2000, 39, 4115-4119. [CrossRef]

40. Lin, R.C.; Chen, Y.C.; Kao, K.S. Two-step sputtered ZnO piezoelectric films for film bulk acoustic resonators. Appl. Phys. A-Mater. Sci. Process. 2007, 89, 475-479. [CrossRef]

41. Li, C.P.; Dai, W.; Xu, S.; Li, X.W.; Gao, C.Y.; Chen, X.M.; Yang, B.H. Local Piezoelectric Properties and Polarity Distribution of ZnO Films Deposited at Different Substrate Temperatures. J. Electron. Mater. 2015, 44, 1095-1099. [CrossRef]

42. Shan, F.K.; Liu, G.X.; Shin, B.C.; Lee, W.J. Annealing Effects of ZnO Thin Films Deposited on Si (100) by Using Pulsed Laser Deposition. J. Korean Phys. Soc. 2009, 54, 916-920. [CrossRef]

43. Choi, S.H.; Kim, J.S. Study on the c-axis preferred orientation of ZnO film on various metal electrodes. Ultramicroscopy 2008, 108, 1288-1291. [CrossRef]

44. Lu, Y.; Emanetoglu, N.W.; Chen, Y. Chapter 13-ZnO Piezoelectric Devices. In Zinc Oxide Bulk, Thin Films and Nanostructures; Jagadish, C., Pearton, S., Eds.; Elsevier Science Ltd.: Oxford, UK, 2006; pp. 443-489.

45. Gardeniers, J.G.E.; Rittersma, Z.M.; Burger, G.J. Preferred orientation and piezoelectricity in sputtered ZnO films. J. Appl. Phys. 1998, 83, 7844-7854. [CrossRef]

46. Kamohara, T.; Akiyama, M.; Kuwano, N. Influence of polar distribution on piezoelectric response of aluminum nitride thin films. Appl. Phys. Lett. 2008, 92, 093506. [CrossRef]

47. Joshi, S.; Nayak, M.M.; Rajanna, K. Effect of post-deposition annealing on transverse piezoelectric coefficient and vibration sensing performance of ZnO thin films. Appl. Surf. Sci. 2014, 296, 169-176. [CrossRef]

48. Janotti, A.; Van de Walle, C.G. Fundamentals of zinc oxide as a semiconductor. Rep. Prog. Phys. 2009, 72, 126501. [CrossRef]

49. Albertsson, J.; Abrahams, S.C.; Kvick, A. Atomic Displacement, Anharmonic Thermal Vibration, Expansivity and Pyroelectric Coefficient Thermal Dependences in ZnO. Acta Crystallogr. Sect. B-Struct. Sci. 1989, 45, 34-40. [CrossRef]

50. Chamorro, W.; Horwat, D.; Pigeat, P.; Miska, P.; Migot, S.; Soldera, F.; Boulet, P.; Mucklich, F. Near-room temperature singledomain epitaxy of reactively sputtered ZnO films. J. Phys. D-Appl. Phys. 2013, 46, 235107. [CrossRef]

51. Menon, R.; Gupta, V.; Tan, H.H.; Sreenivas, K.; Jagadish, C. Origin of stress in radio frequency magnetron sputtered zinc oxide thin films. J. Appl. Phys. 2011, 109, 064905. [CrossRef]

52. Klug, H.P.; Alexander, L.E. X-ray Diffraction Procedures for Polycrystalline and Amorphous Materials; Wiley: New York, NY, USA, 1974.

53. Hala, M.; Kato, H.; Algasinger, M.; Inoue, Y.; Rey, G.; Werner, F.; Schubbert, C.; Dalibor, T.; Siebentritt, S. Improved environmental stability of highly conductive nominally undoped $\mathrm{ZnO}$ layers suitable for n-type windows in thin film solar cells. Sol. Energy Mater. Sol. Cells 2017, 161, 232-239. [CrossRef]

54. Vandepol, F.C.M.; Blom, F.R.; Popma, T.J.A. R.f. planar magnetron sputtered ZnO films I: Structural properties. Thin Solid Films 1991, 204, 349-364. [CrossRef]

55. Water, W.; Chu, S.Y. Physical and structural properties of ZnO sputtered films. Mater. Lett. 2002, 55, 67-72. [CrossRef]

56. Kim, D.; Lee, K.Y.; Gupta, M.K.; Majumder, S.; Kim, S.W. Self-Compensated Insulating ZnO-Based Piezoelectric Nanogenerators. Adv. Funct. Mater. 2014, 24, 6949-6955. [CrossRef]

57. Tsuji, T.; Hirohashi, M. Influence of oxygen partial pressure on transparency and conductivity of RF sputtered Al-doped ZnO thin films. Appl. Surf. Sci. 2000, 157, 47-51. [CrossRef]

58. Kado, T. Structure of Ti films deposited on $\mathrm{MgO}(001)$ substrates. Surf. Sci. 2000, 454, 783-789. [CrossRef]

59. Ahn, K.H.; Baik, S.; Kim, S.S. Change of growth orientation in Pt films epitaxially grown on $\mathrm{MgO}(001)$ substrates by sputtering. J. Mater. Res. 2002, 17, 2334-2338. [CrossRef] 
60. Gupta, V.; Mansingh, A. ISAF XI'98: Proc. XI IEEE Symp. on Applications of Ferroelectrics; Institute of Electrical and Electronics Engineers: Montreux, Switzerland, 1998; p. 113.

61. Bdikin, I.K.; Gracio, J.; Ayouchi, R.; Schwarz, R.; Kholkin, A.L. Local piezoelectric properties of ZnO thin films prepared by RF-plasma-assisted pulsed-laser deposition method. Nanotechnology 2010, 21, 235703. [CrossRef] 